\title{
Spatio-temporal analysis through remote sensing and GIS in Moscow region, Russia
}

\author{
Komal Choudhary $^{1,}$ M.S. Boori ${ }^{1,2,4}$ A. Kupriyanov ${ }^{1,3}$ \\ ${ }^{1}$ Samara National Research University, 34 Moskovskoe Shosse, 443086, Samara, Russia \\ ${ }^{2}$ American Sentinel University, 2260 South Xanadu Way, Suite 310, Aurora, Colorado 80014, USA \\ ${ }^{3}$ Image Processing Systems Institute - Branch of the Federal Scientific Research Centre "Crystallography and Photonics" of Russian Academy of Sciences, 151 \\ Molodogvardeyskaya st., 443001, Samara, Russia \\ ${ }^{4}$ Bonn University, Meckenheimer Allee 166, D-53115 Bonn, Germany
}

\begin{abstract}
Spatio-temporal analysis is a process for city development with growing population and economy for better implementation of planning policies with advance technology. In this research work, three dates (1995, 2005 \& 2016) satellite images were used to mapping and monitoring of Moscow region, Russia. This study focuses on the further classification of the study area into different categories on the basis of use and association by implementing a rule-based classification system on remotely sensed data. This research provides useful and up-to-date information to local land use planners, managers and policy-makers to step up towards sustainable development in Moscow region, Russia.
\end{abstract}

Keywords: Spatio-temporal; land use/cover; remote sensing; GIS

\section{Introduction}

Planning is a widely established approach for managing resource and decision making. It includes the use of collective intelligence and knowledge of future requirements and need to improve environment in which people work and spend their leave time [1]. Hence studying the spatial and temporal LULC changes might provide a prominent basis for more effective land use planning that would keep the ecosystem in balance. At this time research on urban growth has become a very important factor for the interpretation of global environmental changes it has effects on the local environment and the economy growth can be defined as the spread of new developments in urban areas to the surrounding land [2]. Urban growth is responsive for the disorganized use of land resources and energy intrusion into agricultural land. Unplanned urban growth has been responsible for many problems such as poor quality of life, polluted drinking water noise pollution, air pollution etc. The combination of spatial data and analytical methods will provide support to city planners, ecologists and resource managers in their planning and decision making [3-4]. Dynamic spatial urban models provide an enhanced capability for evaluating future development and generating planning.

The technology of remote sensing and GIS includes both aerial and satellite based examination with high resolution and high temporal frequency [5-6]. In this research an attempt has been made to diction the spatio-temporal urban growth dynamics of the Moscow region. To achieve this Landsat satellite data from 1995, 2005 and 2016 for the month of February were analyzed for land use mapping. The urban expansion of Moscow over all 15 years period 1995-2016 was mapped using remote sensing and GIS images.

\section{Study area}

Moscow region is the one of the most densely populated regions in the country and is the second most populated federal region. The Oblast has no official administrative center, it is public authorities are located in Moscow and across other locations in the oblast. As of the 2010 Census, its population was 7,095,120 and 7,231,068 recorded in the 2015 Census. The latitude of the city is $55^{\circ} 45^{\prime} 7^{\prime \prime} \mathrm{N}$ and longitude is $37^{\circ} 36^{\prime} 56^{\prime \prime} \mathrm{E}$. The region is highly industrialized, such as metallurgy, oil refining, mechanical engineering, food, energy and chemical industries [7].

The climate of Moscow region is humid continental, short but warm summers and long cold winters. The average temperature is $3.5^{\circ} \mathrm{C}\left(38.3^{\circ} \mathrm{F}\right)$ to $5.5^{\circ} \mathrm{C}\left(41.9^{\circ} \mathrm{F}\right)$. The coldest months are January and February average temperature of $-9{ }^{\circ} \mathrm{C}\left(16^{\circ} \mathrm{F}\right)$ in the west and $-12^{\circ} \mathrm{C}\left(10^{\circ} \mathrm{F}\right)$ in the east. The minimum temperature is $-54^{\circ} \mathrm{C}\left(-65^{\circ} \mathrm{F}\right)$. Here are more than three hundred rivers in Moscow region. The first largest river is Volga, most river belong to the basin of the Volga. Which itself only crosses a small part in the north of Moscow Oblast. They are mostly fed by melting snow and the flood falls on April-May. The water level is low in summer and increases only with heavy rain. The river freezes over from late November until April.

\section{Material and methods}

The Landsat program is a series of Earth-observing satellite mission jointly managed by NASA and the U.S. geological survey [8]. The first Landsat satellite was launched in 1972 and the most recent one Landsat 8 was launched on February 11, 2013. Data from Landsat 8 has eight spectral bands with spatial resolutions ranging from 15 to $60 \mathrm{~m}$. The Landsat satellite data of 1995, 2005 and 2016 have been used in this study with a spatial resolution of $30 \mathrm{~m}$. The satellite data were checked completely before classification into land use groups [9-10]. There are many techniques available for detecting and recording differences, 
Image Processing, Geoinformation Technology and Information Security / Komal Choudhary, M.S. Boori, A. Kupriyanov

ratios and correlation. The data used in this paper were divided into two categories first satellite data and second ancillary data. Satellite data for the other hand consisted of multi- spectral data acquired by Landsat satellite provided by USGS gloves [11]. Ancillary data include ground truth data for the land use/cover classes and topographic maps. Spectral charts were prepared to distinguish and find out the difference in pixel values of different land use/cover classes in different bands. Primary land use classes were defined, such as agriculture, barren land, forest, settlements, scrubland, water body and wetland. The land use classes are defined in Table 1.

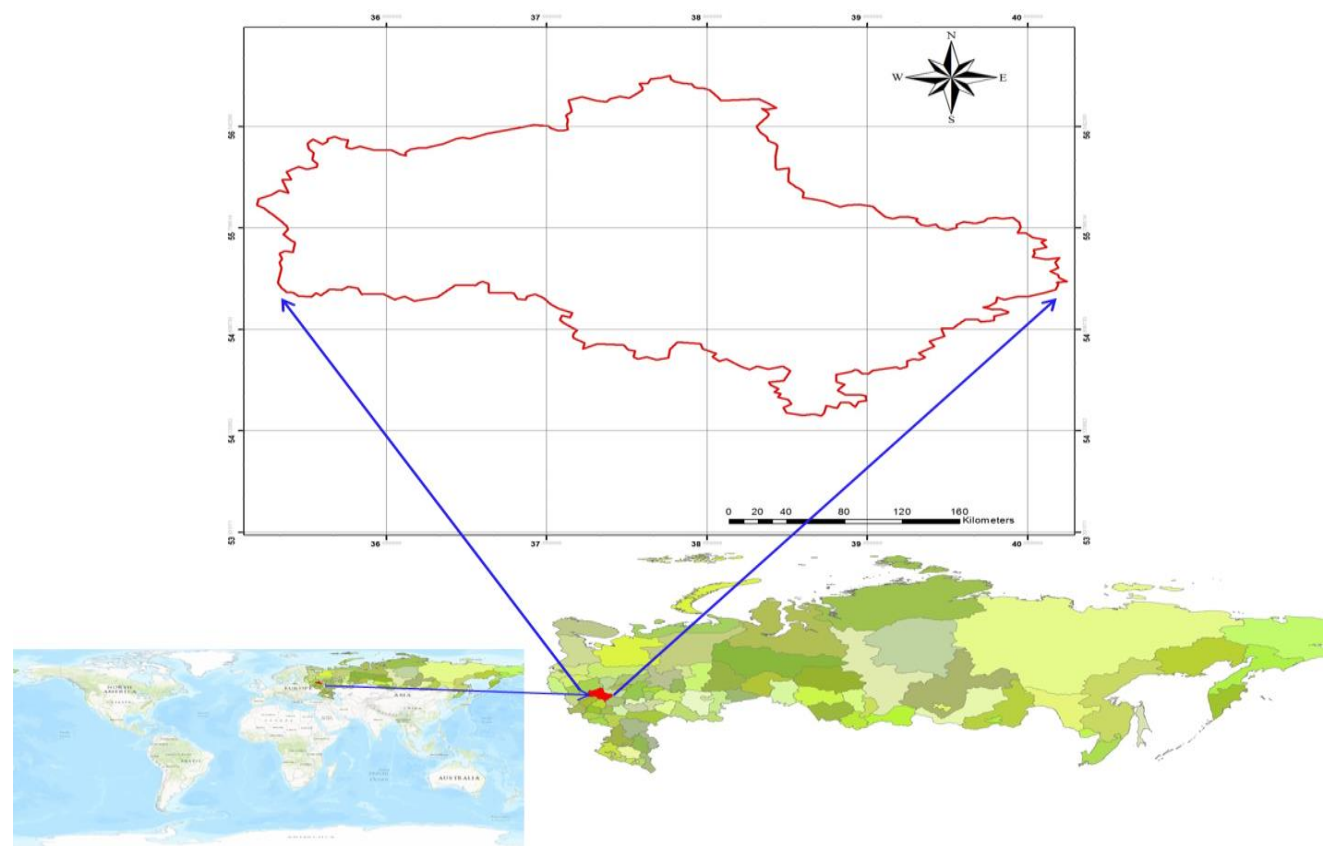

Table 1. Land use classes definitions.

Fig. 1. Location map of the study area in Moscow Region, Russia.

LULC Classes

Agricultural

Barren land

Forest

Scrubland

Settlements

Water body

Wetland
Definition of Land Use Classes

Cultivated areas, crop lands, grass lands, vegetables, fruits etc.

This contains open lands mostly barren but also small vegetation.

Small trees and shrub vegetation area except for vegetation.

Scrub is a plant community describe by vegetation shrubs, often also including grasses and herbs.

Includes construction activities along the coastal dunes as well as sporadic houses within the local village and some governmental buildings.

All the water within land mainly river, ponds, lakes etc.

A wetland is a land area with standing water and low soil fertility.

\subsection{Database preparation}

Any study of land use changes will involve the analysis of both conventional and remotely sensed data. Conventional data is more accurate and site specific, but its collection is time consuming, manpower hungry and difficult to extrapolate over a larger area. Remotely sensed data, on the other hand, has several advantages due to its repetitive and synoptic coverage of large and inaccessible areas in a quick and economical fashion. In the present study both conventional and remotely sensed data were used. The specific satellite images used were Landsat ETM+ (Enhanced Thematic Mapper plus) for 1995 and 2005, Landsat OLI (Operational Land Imager) for 2016, an image captured by a different type of sensors at a resolution of 30m were used for land use/cover classification. These data sets were imported in ArcGIS 10.2 software. Satellite images were making by processing software to create composites. A Trimble hand-held GPS with an accuracy of 10 meters was used to map and collect the coordinates of important land use features during pre- and post-classification field visits to the study area in order to prepare land-use and land-cover maps.

\subsection{Image classification}

Land cover classes are typically mapped from digital remotely sensed data using some sort of supervised, digital image classification. The overall objective of the image classification procedure is to automatically categorize all pixels in an image into land-cover classes or themes and the maximum likelihood classifier quantitatively evaluates both the variance and covariance of the category's spectral response patterns whenever it classifies an unknown pixel. This is why it is considered to be one of the most accurate classifiers - it is based on statistical parameters. Supervised classification was performed here using ground checkpoints and digital topographic maps

\subsection{Land use/cover change detection and analysis}

Land use maps shows in figures 2, were prepared using Landsat data. The accuracy of these classified maps was checked using the GIS tools. The accuracy for these periods is $90 \%$ respectively. There is a big change in land use during this time period. To order increase the accuracy of the land use mapping of the two images, ancillary data, and the result of visual 
Image Processing, Geoinformation Technology and Information Security / Komal Choudhary, M.S. Boori, A. Kupriyanov

interpretation was integrated with the classification results using Arc GIS [12, 13]. The classification of imagery from each individual year, a multi-date, post-classification comparison, change-detection algorithm was used to determine changes during two intervals from 1995-2005 and 2005-2016. This is perhaps the most common approach to change detection. The postclassification approach provides 'from-to' change information which facilitates easy calculation and mapping of the kinds of landscape transformations that have occurred [14]. Accuracy assessment was then carried out at 85 points, 65 from the field data and 20 from existing topographic maps and the land cover map. Specification of these 85 points used a stratified, random method so that all of the different land-cover classes would be represented. In order to increase the accuracy of the land-cover mapping of the two images, ancillary data as well as the result of visual interpretation was integrated with the classification results using GIS [14]. The aim of this was to improve the classification accuracy of the classified image.

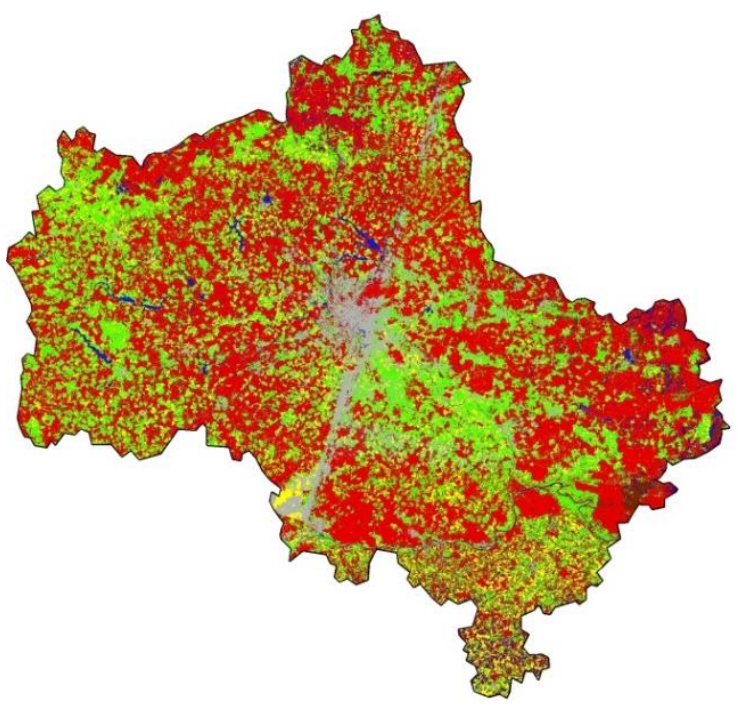

$02 / 1995$

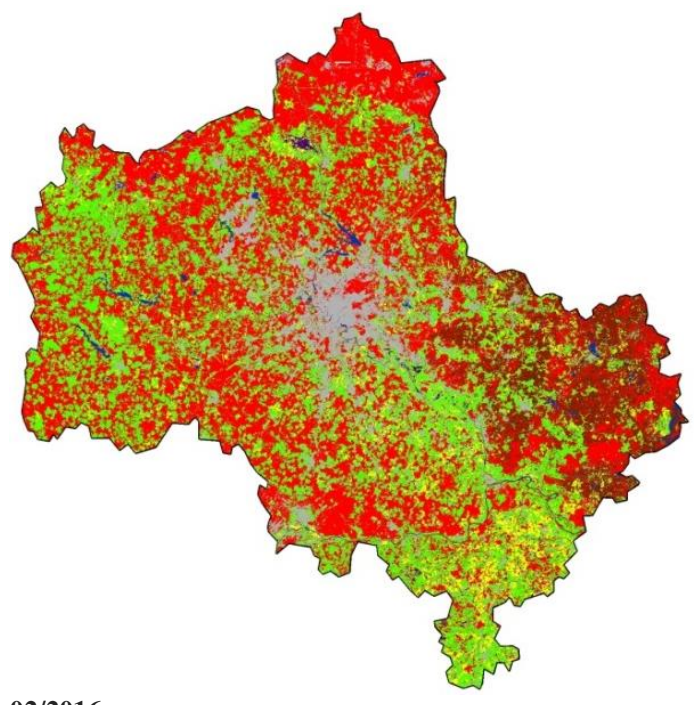

$02 / 2016$

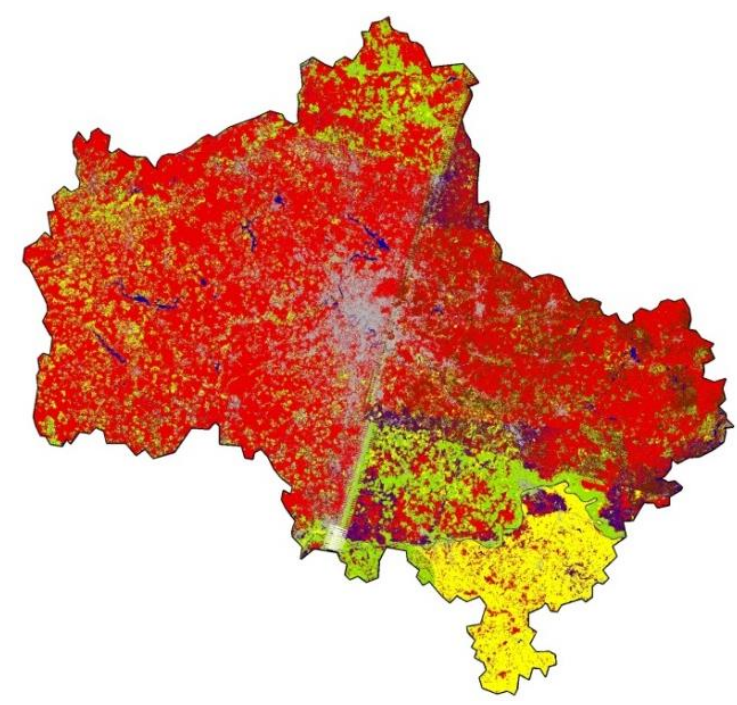

$02 / 2005$

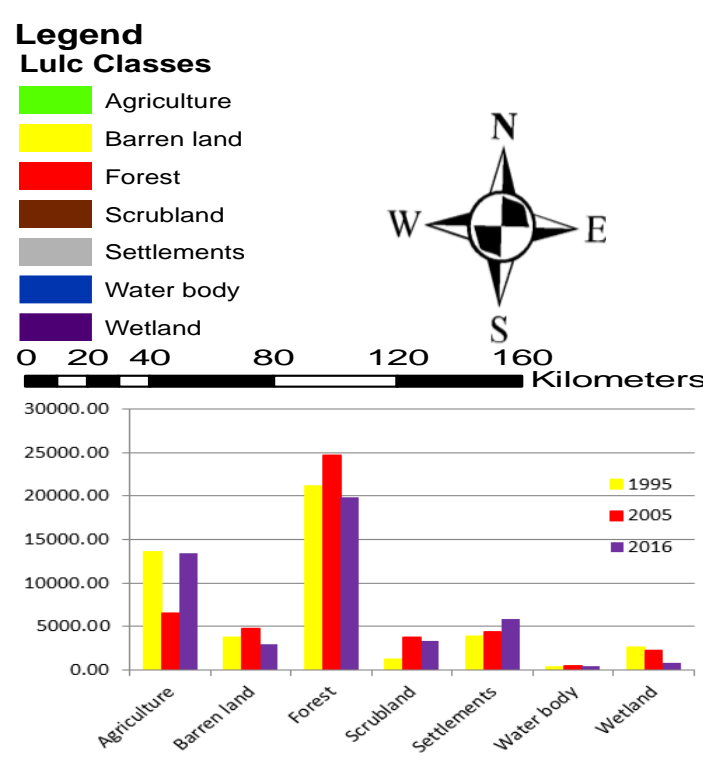

Fig. 2. Land use of Moscow Region, Russia; (a) in 1995, (b) in 2005 and (c) in 2016.

\section{Results and Discussion}

Figure 2 shows land use image after supervised classification. These images provide pattern of land use/cover of the study area. The green color represent agricultural, yellow color barren land, red color forest, gray color settlements, brown color shows the scrubland, blue color shows water body and purple color shows wetlands. All land cover class maps were compared with reference data. Over all classification accuracy of the study area was more than $90 \%$ all three dates.

There is a big change in land use during this time period, as show in the graphical representation of the data in figure 2. Classification maps were generated for all of the sixteen years shown in figure and the individual class area and change statistics are summarizes in table 1 . In 1995 the urban area covered $3898.31 \mathrm{~km}^{2}(8.34 \%)$, but by 2005 it had increased to approximately $4361.75 \mathrm{~km}^{2}(9.33 \%)$ and in 2016 had increased to $5852.00 \mathrm{~km}^{2}(12.51)$. The agricultural area first half decreased from $13673.51 \mathrm{~km}^{2}(29.24 \%)$ in 1995 to $6504.00 \mathrm{~km}^{2}(13.91 \%)$ by 2005 and then increased to $13403.62 \mathrm{~km}^{2}(28.66 \%)$ by 2016 . The forest area increased from $199521135.18 \mathrm{~km}^{2}(45.19 \%)$ to $24671.31 \mathrm{~km}^{2}(52.75 \%)$ by 2005 and then it was decreased 

$\mathrm{km}^{2}(10.09 \%)$ and then it had decreased $2993.18 \mathrm{~km}^{2}(6.40 \%)$ by 2016.

All the urban categories increased continuously, with the urban area increasing by $1953.69 \mathrm{~km}^{2}(4.17 \%)$ since 1995 . Results show that forest area has been most dominant class in the study area for all three dates. The land use transition during the 19952016 periods is shows in table 2 .

Table 2 shows both positive and negative land use/cover changes in the study area from 1995 to 2005, the major change was in agriculture and forest area. Forest was increase $3,536.13 \mathrm{~km}^{2}(7.56)$ and agriculture was decrease $7169.51 \mathrm{~km}^{2}(15.33 \%)$ of the total study area due to hares climatic conditions. From 2005 to 2016 total agriculture area was increase from $6,899.62 \mathrm{~km}^{2}$. In the same time period other classes such as barren land, scrubland, settlements, water body and wetland increase respectively. From 2005 to 2016 total agricultural area was increase from $6,899.62 \mathrm{~km}^{2}$ and other classes settlements and waterbody were increased.

Table 2. Area and amount of change in different land use categories in the study area during 1995 to 2016.

\begin{tabular}{|l|r|r|r|r|r|r|r|}
\hline \multicolumn{7}{|c|}{ Table 2. Area and amount of change in different land use categories in the study area during 1995 to 2016.} \\
\hline Class & \multicolumn{2}{|c|}{1995} & \multicolumn{2}{|c|}{2005} & \multicolumn{2}{|c|}{2016} & \\
\hline Agriculture & 13673.51 & 29.24 & Area KmSq & $\%$ & & Area KmSq & $\%$ \\
\hline Barren land & 3802.63 & 8.13 & 4717.74 & 10.09 & 2993.18 & 6.40 \\
\hline Forest & 21135.18 & 45.19 & 24671.31 & 52.75 & 19896.64 & 42.54 \\
\hline Scrubland & 1268.97 & 2.71 & 3791.82 & 8.11 & 3377.49 & 7.22 \\
\hline Settlements & 3898.31 & 8.34 & 4361.75 & 9.33 & 5852.00 & 12.51 \\
\hline Water body & 408.96 & 0.87 & 430.13 & 0.92 & 449.45 & 0.96 \\
\hline Wetland & 2580.57 & 5.52 & 2291.37 & 4.90 & 795.75 & 1.70 \\
\hline Total & 46768.12 & 100.00 & 46768.12 & 100.00 & 46768.12 & 100.00 \\
\hline
\end{tabular}

Table 3. Land use change showing land encroachment of the study area.

\begin{tabular}{|c|c|c|c|c|c|c|c|c|c|}
\hline \multirow[t]{9}{*}{ 1995-2005 } & CLASS & AGRICULT & BARREN_L & FOREST & SCRUBLAN & SETTLEME & EWATER_BC & WETLAND & Total \\
\hline & Agriculture & 3820.91 & 2119.56 & 4633.85 & 1396.83 & 1318.99 & 15.29 & 503.14 & 13808.57 \\
\hline & Barren land & 867.28 & 1091.05 & 910.37 & 215.43 & 522.59 & 1.39 & 127.87 & 3735.99 \\
\hline & Forest & 990.98 & 583.75 & 15982.20 & 1517.75 & 605.99 & 44.48 & 1384.32 & 21109.46 \\
\hline & Scrubland & 198.75 & 244.62 & 365.54 & 205.70 & 82.00 & 20.85 & 125.09 & 1242.55 \\
\hline & Settlements & 458.66 & 276.59 & 1178.62 & 198.75 & 1599.75 & 13.90 & 151.50 & 3877.76 \\
\hline & Water body & 8.34 & 4.17 & 41.70 & 22.24 & 40.31 & 293.26 & 2.78 & 412.79 \\
\hline & Wetland & 150.11 & 418.35 & 1662.29 & 137.60 & 122.31 & 2.78 & 87.56 & 2581.00 \\
\hline & Total & 6495.04 & 4738.09 & 24774.56 & 3694.29 & 4291.94 & 391.95 & 2382.25 & 46768.12 \\
\hline \multirow[t]{9}{*}{ 2005-2016 } & CLASS & AGRICULT & BARREN_L & FOREST & SCRUBLAN & SETTLEME & WATER_BC & WETLAND & Total \\
\hline & Agriculture & 3926.40 & 622.67 & 1067.43 & 137.60 & 717.18 & 1.39 & 40.31 & 6512.97 \\
\hline & Barren land & 2711.65 & 964.57 & 414.18 & 27.80 & 528.15 & 2.78 & 88.95 & 4738.09 \\
\hline & Forest & 4401.14 & 480.16 & 15697.28 & 2155.70 & 1798.50 & 41.70 & 69.49 & 24643.96 \\
\hline & Scrubland & 1129.97 & 500.88 & 906.20 & 915.93 & 300.21 & 38.92 & 29.19 & 3821.29 \\
\hline & Settlements & 1099.39 & 291.30 & 451.71 & 43.09 & 2354.45 & 27.53 & 45.87 & 4313.33 \\
\hline & Water body & 59.75 & 0.00 & 16.68 & 11.12 & 36.14 & 326.62 & 0.00 & 450.30 \\
\hline & Wetland & 220.88 & 116.75 & 1238.38 & 193.19 & 230.72 & 12.13 & 276.12 & 2288.17 \\
\hline & Total & 13549.18 & 2976.32 & 19791.85 & 3484.42 & 5965.35 & 451.06 & 549.92 & 46768.12 \\
\hline
\end{tabular}

The results show that from 1995 to $2005,3820.91 \mathrm{~km}^{2}$ agriculture areas was stable but $990.98 \mathrm{~km}^{2}$ areas converted from forest to agriculture (table 3). In the same time period $15982.20 \mathrm{~km}^{2}$ forest areas was stable but $1662.39 \mathrm{~km}^{2}$ wetland area was encroached by forest. Maximum stable class was water body, where $293.26 \mathrm{~km}^{2}$ areas were stable from 1995 to 2005 . In second half from 2005 to $20163926.40 \mathrm{~km}^{2}$ agriculture area was stable and $2711.65 \mathrm{~km}^{2}$ barren land, $4401.14 \mathrm{~km}^{2}$ forest and 1129.97 $\mathrm{km}^{2}$ scrubland area converted into agriculture land due to increase of market demand. In this time period there is a not a big change in wetland and maximum bare land area $276.12 \mathrm{~km}^{2}$ was stable. Scrubland $906.20 \mathrm{~km}^{2}$ and wetland $1238.38 \mathrm{~km}$ area was converted into forest area which shows governmental protection from 2005 to 2016 . Since 2005 to $2016,2354.45 \mathrm{~km}^{2}$ settlements area was stable but $1798.50 \mathrm{~km}^{2}$ forest area was converted into settlements. In the second half again water body area was highly stable area around $326.62 \mathrm{~km}^{2}$.

As show by our study, land -cover change is mainly driven by the expansion of socio-economic activities. The increase of agricultural areas, if poorly managed has impacts above those previously mentioned changes in the soil water cycle, nutrient 
Image Processing, Geoinformation Technology and Information Security / Komal Choudhary, M.S. Boori, A. Kupriyanov

depletion and an increased risk of soil erosion and land degradation even though the expansion of croplands leads to a growth in agricultural outputs like food and fibers to positively impact on the country's economy and human well- being.

As well as the huge increased in agricultural area there has also been a considerable increase in urban settlements. Such changes require rapid adjustments to land management in order to avoid crises in food. From a socio-economic point of view this means not only a loss of ecosystem services, but also a decline of earn money and cultural values, not to mention a subsequent reduction of income from tourism. A consequence of this is to make protected areas some of the few remaining zones where fuel wood, rich pastures and game resources are left and so they attract more and more legal activities.

\section{Conclusion}

In this new period of globalization cities should have quality infrastructure, energy and environment condition to sustain growth and attract foreign investment. The planning authorities should adopt new technologies such as remote sensing and GIS to address these issues. Remote Sensing and GIS are adequate of providing the necessary information and intelligence for planning proposal. In this research remote sensing and GIS have been unified to exhibit the changes in urban development and its future growth trends. This study focus on discover the expansion of the urban area of Moscow region. A large percentage of barren land was transformed into urban area during the study period. The urban growth shows maximum detail on the outskirts of the region. This expansion also indicates of industrial growths. Only remote sensing data can provide complete spatial information for the efficient assignment of urban growth in developing countries over the time period.

\section{Acknowledgements}

This data work is financially supported by the Russian Scientific Foundation (RSF), grant no. 14-31-00014 "Establishment of a Laboratory of Advanced Technology for Earth Remote Sensing”.

\section{References}

[1] Baker WL. A Review of Models of Landscape Change. Landscape Ecology 1989; 2: 111-133.

[2] Bauer T, Steinnocher K. Per Parcel Land Use Classification in Urban Areas Applying a Rule-Based Technique. GeoBIT/GIS 2001; 6: $24-27$.

[3] Boori MS, Choudhary K, Kupriyanov A. Vulnerability analysis on Hyderabad city, India. Computer Optics 2016; 40(5): 752-758. DOI: 10.18287/24126179-2016-40-5-752-758.

[4] Alemayehu M. Forage Production in Ethiopia: A case study with implications for livestock production. Ethiopian Society of Animal Production (ESAP), Addis Ababa, Ethiopia, 2002.

[5] Allan J. Sensors, Platforms and Applications; Acquiring and Managing Remotely Sensed Data. Application of Remote Sensing in Agriculture. Butterworths, London, 1990.

[6] Fang S, Gertner GZ, Sun Z, Anderson AA. The impact of interactions in spatial simulation of the dynamics of urban sprawl. Landscape and Urban Planning 2005;73: 294-306.

[7] Henriquez C, Azocar G, Romero H. Monitoring and modeling the urban growth of two medium-sized Chilean cities. Habitat International 2006; 30: 945964.

[8] Asner G. Contributions of multi-view angle remote sensing to land-surface and biogeochemical research, Remote Sensing of Environment 2000; 18: 137162.

[9] Boori MS, Choudhary K, Soifer VA, Sugimoto A. Computer simulation of satellite data for urban expansion analysis. International Journal of Mathematics and Computers in Simulation 2016; 10: 142151.

[10] Boori MS, Kuznetsov AV, Choudhary K, Kupriyanov A. Satellite image analysis to evaluate the urban growth and land use changes in the city of Samara from 1975 to 2015. Computer Optics 2015; 39(5): 818-822. DOI: 10.18287/0134-2452-2015-39-5-818-822.

[11] Dewan AM, Yamaguchi Y. Land use and land cover change in Greater Dhaka, Bangladesh: Using remote sensing to promote sustainable urbanization. Applied Geography 2009; 29: 390-401.

[12] Boori MS, Choudgary K, Kupriyanov A, Sugimoto A, Kovelskiy V. Monitoring land use/cover change detection through remote sensing and GIS techniques in Eastern Siberia, Russia. SGEM 2016 Conference Proceedings 2016; 2: 971-978. DOI:10.5593/SGEM2016/B22/S10.124.

[13] Boori MS, Choudhary K, Kupriyanov A, Sugimoto A, Evers M. Natural and environmental vulnerability analysis through remote sensing and GIS techniques: A case study of Indigirka River basin, Eastern Siberia, Russia. Proc. Of SPIE 2016; 10005(100050U): 1-10. DOI:10.1117/12.2240917.

[14] Choudhary K, Boori MS, Kupriyanov A. Landscape Analysis through Remote Sensing and GIS Techniques: A Case Study of Astrakhan, Russia. SPIE 2017 Conference Proceedings, SPIE 2017; 10225: 102251U-1. DOI: 10.1117/12.2266245. 